\title{
Seton drainage prior to transanal advancement flap repair: useful or not?
}

\author{
Litza E. Mitalas • Jan J. van Wijk • \\ Martijn P. Gosselink • Pascal Doornebosch • \\ David D. E. Zimmerman • W. Rudolph Schouten
}

Accepted: 8 June 2010 / Published online: 20 July 2010

(C) The Author(s) 2010. This article is published with open access at Springerlink.com

\begin{abstract}
Introduction Transanal advancement flap repair (TAFR) provides a useful tool in the treatment of high transsphincteric fistulas. Recent studies indicate that TAFR fails in one out of three patients. Until now, no definite predictive factor for failure has been identified. Although some authors have reported that preoperative seton drainage might improve the outcome of TAFR, this could not be confirmed by others. We conducted the present study to assess the influence of preoperative seton drainage on the outcome of TAFR in a relatively large series.

Methods Between December 1992 and June 2008, a consecutive series of 278 patients [M/F=179:99, median age 46 years (range, 19-73 years)] with cryptoglandular, transsphincteric fistula, passing through the upper or middle third of the external anal sphincter underwent TAFR. Patients were recruited from the colorectal units of two university hospitals (Erasmus Medical Center, Rotterdam, $n=211$; and Leiden University Medical Center, Leiden, $n=67$ ). Baseline characteristics did not differ between the two clinics. Sixty-
\end{abstract}

No financial support was received for this study.

L. E. Mitalas · J. J. van Wijk · M. P. Gosselink •

D. D. E. Zimmerman • W. R. Schouten $(\bowtie)$

Colorectal Research Group, Department of Surgery,

Erasmus Medical Center,

H 181 's Gravendijkwal 230,

3015 CE Rotterdam, The Netherlands

e-mail: w.r.schouten@erasmusmc.nl

\section{E. Mitalas}

Department of Immunology, Erasmus Medical Center,

Rotterdam, The Netherlands

P. Doornebosch

Department of Surgery, Leiden University Medical Center,

Leiden, The Netherlands eight of these patients underwent preoperative seton drainage for at least 2 months and until the day of the flap repair. Results Median healing time was 2.2 months. In patients without preoperative seton drainage, the healing rate was $63 \%$, whereas the healing rate was $67 \%$ in patients who underwent preoperative seton drainage. This difference was not statistically significant. No differences in healing rates were found between the series from Leiden and Rotterdam. Conclusion Preoperative seton drainage does not improve the outcome of TAFR.

Keywords Perianal fistula $\cdot$ Transanal advancement flap repair $\cdot$ Seton $\cdot$ Drainage

\section{Introduction}

The principle goal in the treatment of transsphincteric fistulas passing through the upper or middle third of the external anal sphincter is healing of the fistula, at the same time preventing damage to the external anal sphincter. Although transanal advancement flap repair (TAFR) provides a useful tool in achieving this goal, it has become clear that this procedure fails in one out of three patients [1-7]. Until now, no predictive factor for failure has been identified. Recently, we examined the outcome of repeat flap repair in 26 patients, who encountered a failure after the initial procedure [8]. In all these patients, we noticed complete healing of the advancement flap, except at the site of the original internal opening. This remarkable clinical finding and the lack of predictive factors for failure suggest that persistence of the fistula might be due to ongoing disease within the remaining fistulous tract. This theory raises the question whether the detrimental effect of this ongoing disease can be diminished by preoperative seton 
drainage. According to some authors, preoperative seton drainage is beneficial, since it allows drainage of the fistulous tract, thereby reducing the inflammatory activity within the tract and resolving secondary tracts $[5,9,10]$. Although two reports $[3,5]$ indicate that preoperative seton drainage improves the healing after TAFR, this beneficial effect could not be confirmed by others $[6,11]$. However, the reported series were rather small, and study populations were often of heterogeneous consistency, including patients with a rectovaginal fistula and patients with fistulas due to Crohn's disease. The aim of the present study was to assess the effect of preoperative seton drainage on the outcome of TAFR in a relatively large series of patients with a high transsphincteric fistula of cryptoglandular origin.

\section{Patients and methods}

Between December 1992 and June 2008, a consecutive series of 278 patients with a cryptoglandular, transsphincteric fistula, passing through the upper or middle third of the external anal sphincter underwent TAFR. The patients were recruited from the colorectal units of two university hospitals (Erasmus Medical Center, Rotterdam, $n=211$ and Leiden University Medical Center, Leiden, $n=67$ ). Baseline patient characteristics did not differ between the two clinics. Sixty-eight of these patients underwent preoperative seton drainage for at least 2 months until the day of flap repair. In the Leiden University Medical Center and in the Erasmus Medical Center, TAFR after preoperative seton drainage was performed in 33 and 35 patients, respectively. Clinical charts were studied to analyze the reason for seton placement.

\section{Exclusion criteria}

Patients with a rectovaginal fistula or a fistula due to Crohn's disease were excluded from the present series.

\section{Imaging}

Prior to flap repair, all patients underwent either hydrogen peroxide-enhanced endoanal ultrasonography or endoanal magnetic resonance imaging in order to assess course of the transsphincteric fistulous tract. These imaging techniques were also performed to identify the location of the internal opening and to detect the presence of any horseshoe extensions and associated abscesses.

\section{Surgical technique}

Patients referred to the Erasmus Medical Center underwent complete mechanical bowel preparation (polyethylene gly- col). In the Leiden University Medical Center a single phosphate enema was instilled on the day of the operation. After induction of general endotracheal anesthesia, metronidazole $(500 \mathrm{mg})$ together with cefuroxime $(1500 \mathrm{mg})$ was administered intravenously. With the patient in prone jackknife position, the seton, if present, was removed. The external opening was enlarged, and the fistulous tract was excised through this opening until the border of the external anal sphincter. The internal opening of the fistula was exposed using a Lone star retractor (Lone star Retractor System, Lone Star Medical Products ${ }^{\circledR}$, Inc. Houston, TX). The crypt-bearing tissue around the internal opening as well as the overlying anodermis was then excised.The fistulous tract was cored out of the sphincters. The defect in the internal anal sphincter was closed with absorbable sutures. A flap consisting of mucosa, submucosa, and some of the most superficial fibers of the internal anal sphincter was raised from the level of the dentate line and mobilized over a distance of 4 to $6 \mathrm{~cm}$ proximally. The flap was advanced and sutured to the neodentate line with absorbable sutures.

\section{Postoperative care}

Patients who underwent TAFR at the Erasmus Medical Center in Rotterdam were immobilized for 5 days. Patients received a clear liquid diet for 5 days. During this time period, metronidazole and cefuroxime were administered intravenously three times daily. The patients who underwent TAFR at the Leiden University Medical Center were immobilized for a minimum of $24 \mathrm{~h}$ and did not receive additional antibiotics.

Follow-up

All patients visited the outpatient clinic at 6 and 18 weeks and 12 months, postoperatively. Healing of the fistula was defined as complete wound healing and closure of all external openings in combination with absence of symptoms.

\section{Results}

The charts of 278 consecutive patients who had undergone TAFR for cryptoglandular, transsphincteric fistulas, passing through the upper or middle third of the external anal sphincter were analyzed. Median healing time was 2.2 months. The present series comprised 179 men and 99 women. Median age at the time of repair was 46 years (range, 19-73years). In patients without preoperative seton drainage, the healing rate was $63 \%$, whereas the healing rate was $67 \%$ in patients who underwent preoperative seton drainage. This difference was not statistically significant $(p=0.40)$. Baseline fistula and patient characteristics did not 
differ between the patients with and without preoperative seton drainage (Table 1). No differences in healing rates were found between the series from Leiden and Rotterdam (Table 2).

\section{Discussion}

Perianal fistulas passing through the upper or middle third of the external anal sphincter present a challenge to many surgeons. Despite new treatment modalities such as closure of the fistulous tract with fibrin glue or a bioprosthetic plug, transanal advancement flap repair still provides a useful tool in the treatment of these fistulas. It enables healing of the fistula without damage of the external sphincter and consequent fecal incontinence. Initially, the reported healing rates varied between $84 \%$ and $100 \%$ [12-15]. However, during the last decade, it has become clear that TAFR fails in one out of three patients [1-7]. Until now, no definite risk factor for failure has been identified. Recently, we examined the outcome of repeat flap repair in 26 patients, who encountered a failure after the initial procedure [8]. In all these patients, we noticed complete healing of the advancement flap, except at the site of the original internal opening. This remarkable clinical finding and the lack of predictive factors for failure suggest that persistence of the fistula might be due to ongoing disease within the remaining fistulous tract. Obliteration of this tract with a surgical adhesives such as fibrin glue and Bio Glue ${ }^{\circledR}$ as an adjunct to flap repair [7, 16-18] has not only failed to improve the healing rate, but even had a detrimental effect on the outcome. Some authors advocate preoperative seton drainage, since it allows drainage of the fistulous tract, thereby reducing the inflammatory activity within the tract and resolving secondary tracts $[5,9,10]$. In a retrospective

Table 1 Comparison of baseline patients and fistula characteristics between patients with and without preoperative seton drainage

\begin{tabular}{llll}
\hline & & Seton & No seton \\
\hline Internal opening & Posterior & $63 \%$ & $70 \%$ \\
& Anterior & $29 \%$ & $26 \%$ \\
& Lateral & $7 \%$ & $4 \%$ \\
Horseshoe extension & Yes & $50 \%$ & $47 \%$ \\
& No & $50 \%$ & $53 \%$ \\
Prior attempts at repair & Yes & $59 \%$ & $56 \%$ \\
Gender Ratio (M/F) & No & $41 \%$ & $44 \%$ \\
Age (range) & & $2: 1$ & $2: 1$ \\
Body mass index & & $43(21-69)$ & $46(19-73)$ \\
Smoking & & 24 & 25 \\
& Yes & $56 \%$ & $52 \%$ \\
& No & $44 \%$ & $48 \%$ \\
\hline
\end{tabular}

Table 2 Healing rates in patients with and without preoperative seton drainage

\begin{tabular}{lccc}
\hline & Leiden & Rotterdam & Both centers \\
\hline Seton drainage & $64 \%$ & $69 \%$ & $67 \%$ \\
No seton drainage & $68 \%$ & $62 \%$ & $63 \%$ \\
Overall & $66 \%$ & $63 \%$ & $64 \%$ \\
\hline
\end{tabular}

study, Sonoda and co-workers were the first to observe a beneficial effect [3]. In a relatively large series of 105 patients, 56 patients underwent preoperative seton drainage. Comparing patients with and without preoperative seton drainage, they found a healing rate of $73.2 \%$ and $51.2 \%$, respectively. This difference was statistically significant. However, their study included a large number of patients suffering from a rectovaginal fistula and patients with a fistula due to Crohn's disease. Only 44 patients presented with a fistula of cryptoglandular origin. Unfortunately, the authors omitted to provide data regarding preoperative seton drainage in this group of patients. Van der Hagen and co-workers described the outcome of TAFR after preoperative seton drainage in 23 patients with a fistula of cryptoglandular origin [5]. Five of these patients also had a diverting stoma. Although the healing rate was quite high (78\%), no comparison was made with patients undergoing TAFR alone. Two other studies, conducted by Zimmerman et al. and by Van Koperen and co-workers indicate that preoperative seton drainage does not affect the outcome of TAFR [6, 11].

The present series comprised 278 patients. Sixty-eight of our patients underwent seton drainage prior to TAFR. Since we were not able to show any beneficial effect of preoperative seton drainage in this relatively large series, it seems unlikely that this type of preoperative treatment provides a useful tool to enhance the outcome of TAFR. However, a drawback of the present study is its retrospective design. We have considered the possibility that the complexity of the fistula might have been a reason to allow preoperative seton drainage. Reviewing the clinical charts, we found no specific reasons for seton placement. Both centers are tertiary referral centers, and the major part of the patients was referred from smaller hospitals. A part of these patients were admitted to one of both centers with a seton in situ. Many surgeons are not confident with treating high transsphincteric fistulas, and the policy of some of these referring surgeons is to place a seton to bide the time until definite treatment. Moreover, we analyzed the fistula characteristics. We found no differences in the baseline fistula and patients characteristics between patients with and without preoperative seton drainage. Patients admitted, to any of the centers, with a seton did not have a more complex fistulae. Moreover, clinical chart review revealed 
no specific reasons for seton placement. The main reason was the fact that most surgeons are uncomfortable in treating patients with a high transsphincteric fistula. To bide the time until definite surgery, some referring surgeons have the policy to place a seton in order to minimize complaints and prevent acute anal sepsis. Taking into account the facts stated above, in our opinion, the risk on selection bias is negligible. In our opinion, preoperative seton drainage does not positively affect the outcome of TAFR by diminishing the inflammatory activity in the fistulous tract.

All our patients who underwent TAFR at the Erasmus Medical Center, in Rotterdam, were immobilized for 5 days and received a clear liquid diet for 5 days. During this time period, metronidazole and cefuroxime were administered intravenously three times daily. The patients who underwent TAFR at the Leiden University Medical Center were immobilized for a minimum of $24 \mathrm{~h}$ and did not receive additional antibiotics. Until now, there is no evidence for the use of antibiotics, liquid diets, mechanical bowel preparation, or for keeping patients immobilized. The lack of differences in healing rates found between the two clinics might indicate that these precautions have no beneficial effect. Further research is warranted to elucidate this subject. So far, no factors have been identified that affect the outcome of TAFR. Persistence of the fistula seems to be caused by ongoing disease in the remaining fistulous tract. Further research is warranted to assess the impact of this ongoing disease on the outcome of flap repair.

\section{Conclusion}

Seton drainage prior to TAFR does not improve the outcome.

Open Access This article is distributed under the terms of the Creative Commons Attribution Noncommercial License which permits any noncommercial use, distribution, and reproduction in any medium, provided the original author(s) and source are credited.

\section{References}

1. Miller GV, Finan PJ (1998) Flap advancement and core fistulectomy for complex rectal fistula. Br J Surg 85(1):108-110

2. Schouten WR, Zimmerman DD, Briel JW (1999) Transanal advancement flap repair of transsphincteric fistulas. Dis Colon Rectum 42(11):1419-1422, discussion 1422-1423

3. Sonoda $\mathrm{T}$ et al (2002) Outcomes of primary repair of anorectal and rectovaginal fistulas using the endorectal advancement flap. Dis Colon Rectum 45(12):1622-1628

4. van der Hagen SJ et al (2006) Long-term outcome following mucosal advancement flap for high perianal fistulas and fistulotomy for low perianal fistulas: recurrent perianal fistulas: failure of treatment or recurrent patient disease? Int J Colorectal Dis 21(8):784-790

5. van der Hagen SJ et al (2005) Staged mucosal advancement flap for the treatment of complex anal fistulas: pretreatment with noncutting setons and in case of recurrent multiple abscesses a diverting stoma. Colorectal Dis 7(5):513-518

6. Zimmerman DD et al (2003) Smoking affects the outcome of transanal mucosal advancement flap repair of trans-sphincteric fistulas. Br J Surg 90(3):351-354

7. Mizrahi N et al (2002) Endorectal advancement flap: are there predictors of failure? Dis Colon Rectum 45(12):1616-1621

8. Mitalas LE et al (2007) Repeat transanal advancement flap repair: impact on the overall healing rate of high transsphincteric fistulas and on fecal continence. Dis Colon Rectum 50(10):1508-1511

9. Parks AG, Stitz RW (1976) The treatment of high fistula-in-ano. Dis Colon Rectum 19(6):487-499

10. Williams JG et al (2007) The treatment of anal fistula: ACPGBI position statement. Colorectal Dis 4:18-50, 9 Suppl

11. van Koperen PJ et al (2008) Long-term functional outcome and risk factors for recurrence after surgical treatment for low and high perianal fistulas of cryptoglandular origin. Dis Colon Rectum 52:1196-1197

12. Wedell J et al (1987) Sliding flap advancement for the treatment of high level fistulae. Br J Surg 74(5):390-391

13. Oh C (1983) Management of high recurrent anal fistula. Surgery 93(2):330-332

14. Kodner IJ et al (1993) Endorectal advancement flap repair of rectovaginal and other complicated anorectal fistulas. Surgery 114 (4):682-689, discussion 689-690

15. Aguilar PS et al (1985) Mucosal advancement in the treatment of anal fistula. Dis Colon Rectum 28(7):496-498

16. Ellis CN, Clark S (2006) Fibrin glue as an adjunct to flap repair of anal fistulas: a randomized, controlled study. Dis Colon Rectum 49(11): 1736-1740

17. van Koperen PJ et al (2008) Fibrin glue and transanal rectal advancement flap for high trans-sphincteric perianal fistulas; is there any advantage? Int J Colorectal Dis 23:697-701

18. Alexander SM et al (2008) Obliteration of the fistulous tract with BioGlue adversely affects the outcome of transanal advancement flap repair. Tech Coloproctol 12(3):225-228 